\title{
INTERVENCIÓN POR EQUIVOCACIÓN: LA "INVASIÓN DEL TRANVÍA" A CIUDAD JUÁREZ EN FEBRERO DE 1912
}

\author{
Por \\ Lawrence Douglas Taylor Hansen*
}

\begin{abstract}
RESUMEN
En este artículo de corte histórico, se relatan a detalle los antecedentes y el suceso mismo conocido como la "invasión del tranvía", que aconteció el 14 de febrero de 1912 en la frontera Ciudad Juárez-El Paso. Se describe la importancia de este hecho de nuestra historia, al parecer irrelevante, pero que pudo tener grandes repercusiones en las relaciones internacionales entre México y los Estados Unidos, al ser un reflejo de la política intervencionista que adoptaron los estadunidenses ante los movimientos armados desarrollados durante la Revolución Mexicana.
\end{abstract}

\begin{abstract}
This brief historical account relates in detail the events leading up to what is known as the "streetcar invasion," of February 14, 1912, at the El Paso-Ciudad Juarez border, as well as describing the incident itself. Emphasis is placed on the importance of this incident in our history. Though apparently of little importance, it provoked great repercussions in the relations between Mexico and the United States, since it reflected the interventionist policy which the United States adopted wiht respect to the development of armed military movements in Mexico during the 1910 mexican revolution.
\end{abstract}

En el transcurso del año de 1912 ocurrió un acontecimiento que en sí mismo era de menor significancia, pero que, dentro del contexto global de la Revolución Mexicana, tuvo importantes repercusiones sobre las relaciones entre México y Estados Unidos. Este evento consistio en la llamada "invasión del tranvía", cuando un grupo de soldados estadounidenses entraron brevemente al territorio mexicano por equivocacion, un acto que representó una visible manifestación de la política de intervención militar que muchos de sus connacionales solicitaron que su gobierno adoptara con respecto a México como un posible antídoto al desorden y destrucción causada por esta gran contienda.

* Investigador de el Departamento de Administración Pública de El Colegio de la Frontera Norte. 
Para ubicar adecuadamente la "invasión del tranvía" de 1912 dentro del panorama de la revolución en su totalidad, hay que remontarnos a finales de mayo de 1911, con la caída del régimen del presidente Porfirio Díaz. El triunfo de las fuerzas insurrectas encabezadas por Francisco I. Madero no resultó en la inauguración de un periodo de paz en México. Aunque la administración interina de Francisco León de la Barra sólo experiment 6 disturbios relativamente menores, por ejemplo, los continuos ataques de los magonistas y la reanudación de la revuelta de los zapatistas en Morelos y otros estados del sur de México. En cambio, el gobierno encabezado por Madero, que se inició el 7 de octubre de 1911, tuvo que afrontar, además de estas rebeliones, otra serie de desafíos militares, comenzando con el que fue encabezado por Bernardo Reyes en el otoño de 1911 y terminando con el golpe de estado felicista-huertista de febrero de 1913 que resultó en la caída y muerte del presidente.

La primera de estas revueltas, la que fue dirigida por Reyes, se acabó después de un tiempo y en realidad no llegó a ser más que una conspiración. Otro movimiento rebelde, encabezado por Emilio Vázquez Gómez, se organizó casi al mismo tiempo. A finales de octubre de 1911, Vázquez Gómez se dirigió a San Antonio, donde organizó una junta revolucionaria. El 29 de diciembre, después de la extinción de la rebelión reyista, este jefe redactó una carta que se publicó en varios periódicos mexicanos y estadounidenses, invitando a los elementos inconformes a sublevarse en contra del gobierno de Madero. A principios de enero de 1912, los dirigentes del movimiento cambiaron su base de operaciones a El Paso. ${ }^{1}$

La mayor parte del apoyo a la revuelta se concentraba en la región fronteriza entre los dos países, sobre todo en Chihuahua, donde la desmovilización de las fuerzas revolucionarias, los problemas relativos a la tenencia de la tierra, y la sustitución del candidato a la vicepresidencia Francisco Vázquez Gómez —el hermano de Emilio— por José María de Pino Suárez en las elecciones de 1911, había provocado considerable descontento popular, sobre todo en el estado de Chihuahua. Entre los dirigentes del movimiento había algunos ex magonistas, como Emilio P. Campa, otros ex magonistas quienes se habían aliado con Madero durante la insurrección de 1910-1911, por ejemplo, José Inés Salazar, y ex reyistas como el coronel Francisco A. Chapa (Henderson, 1979:22-26; Coerver y Hall, 1984:44).

La proyectada rebelión tardó en desarrollarse. A finales de noviembre y principios de diciembre de 1911, el coronel de milicia Antonio Rojas encabezó una pequeña revuelta en el mineral de Dolores en el Distrito de

1 Para información más extensa sobre los orígenes del movimiento vazquista, véase Francisco R. Almada (1964). 
Guerrero, pero, confrontado con la llegada inminente de una sección de rurales dirigida por el capitán Martiniano Servín, tuvo que huir hasta Sonora y eventualmente decidió rendirse el 1 de enero de 1912. El 31 de enero de 1912, el 240. Cuerpo Rural que guarnicionaba a Ciudad Juárez, se amotinó debido a ordenes por parte del gobiemo federal de reducir el tamaño de su tropa, así como la falta de dinero para pagar a los soldados dados de baja. Los amotinados inicialmente se declararon seguidores de Emiliano Zapata, quien había sido el primer jefe revolucionario importante en levantarse en armas en contra del régimen de Madero. Posteriormente, empero, anunciaron su adhesión al programa revolucionario promulgado por Vázquez Gómez (El Paso Morning Times, 1 y 2 de febrero de 1911; Almada, 1964:276-279; Sánchez, 1976-1977:11-12).

Las autoridades estatales y nacionales estadounidenses se preocupaban de que este nuevo brote de violencia podría conducir a un combate de mayores proporciones, tal como había ocurrido en Ciudad Juárez en mayo de 1911. En todo caso, muchos mexicanos se habían refugiado en El Paso, y a una porción de las unidades militares del ejército estadounidense destacadas en el Fuerte Bliss les fue ordenado ocupar posiciones a lo largo de la frontera en esta ciudad y sus alrededores. Algunos miembros del Consejo Municipal de El Paso y de la Chamber of Commerce (Cámara de Comercio) de aquella ciudad aprobaron resoluciones que solicitaban que el presidente Taft enviara a soldados estadounidenses a México para proteger las vidas y propiedades de sus connacionales allí, hasta que el gobierno federal mexicano pudiera restaurar su control sobre la región. Sin embargo, a final de cuentas, únicamente pidieron a Taft que tomara las medidas necesarias para evitar que la violencia provocada por combates revolucionarios en las cercanías de Ciudad Juárez afectara al vecino pueblo de El Paso. ${ }^{2}$ Oscar B. Colquitt, el gobernador de Texas, hizo esta misma petición a través del Texas Rangers, a las autoridades mexicanas en Ciudad Juárez. Al mismo tiempo, solicitó al presidente Taft que "avisara que ellos [los soldados mexicanos] no deberían tirar en la dirección de El Paso como en el caso de la última batalla de Juárez. En caso necesario, tomaré medidas drásticas para evitar su repetición." ${ }^{3}$ (El Paso Morning, 2 y 3 de febrero de 1912).

En un esfuerzo por complacer a Colquitt y a los ciudadanos de El Paso, Taft les informó que había dado órdenes "con la idea de solucionar las

2 Telegrama de Enrique C. Llorente al secretario de Relaciones Exteriores en México, 1 de febrero de 1912, en Isidro Fabela y Josefina E. Fabela (1960-1973:77) y El Paso Morning Times, 3 de febrero de 1912 .

${ }_{3}$ Transcripción del telegrama de O.B. Colquitt a W.S. Clayton, el presidente de la Cámara de Comercio de El Paso. 
dificultades en Juárez" y que había aconsejado al secretario de Guerra, Henry L. Stimson, sobre "la necesidad de actuar". El estado mayor del ejército estadounidense preparó una serie de planes para realizar operaciones militares en México, en caso que fuera necesario llevarlos a cabo para proteger las vidas de los estadounidenses que se encontraban radicados allí. Al general de brigada J.W. Duncan, al comandante del Departamento Militar de Texas, y a sus contrapartes a lo largo de la frontera, les fue otorgado permiso para trasladar una porción de sus fuerzas - con la excepción de las unidades de milicia estatal-a puntos más cercanos a la frontera en caso de una "emergencia repentina", aunque bajo ninguna circunstancia los soldados estadounidenses podían entrar a México. ${ }^{4} \mathrm{Con}$ la aprobación de Duncan, el coronel Edgar Z. Steever, el comandante del 4to. Regimiento de Caballería, cuya responsabilidad incluía la defensa de la región de El Paso, comunicó a las autoridades militares en Ciudad Juárez que deberían tomar medidas para evitar que los combates causaran daños a la población del otro lado del río (El Paso Morning 3, 5, 6 y 9 de febrero de 1912).

El gobernador Colquitt reaccionó favorablemente a la respuesta dada por el gobierno federal, al pensar que representaba una política más agresiva por parte de éste, aunque pensaba, erroneamente, que Taft contemplaba seriamente intervenir militarmente en México como resultado de la crisis de Ciudad Juárez. La política beligerante de Colquitt sugirió la posibilidad de que el estado de Texas emprendiera operaciones militares en México de manera unilateral. El coronel Steever reportó que necesitaría un batallon de soldados completo "en caso que el gobernador de Texas decida implementar las medidas drásticas que propone". Los secretarios del Departamento de Guerra y del Departamento de Estado expresaban su comprensión de la posición difícil en que se encontraba Colquitt, pero querían que el gobernador de Tejas "entendiera que esto es un asunto que tiene que ser tratado por las autoridades federales y no las de cualquier estado". 5

4 El historiador estadounidense J. Fred Rippy asevera que cerca de 100000 soldados de línea y voluntarios, fueron concentrados en las zonas contiguas a la frontera con México, que puede ser una cifra algo inflada, si tomamos en consideración que el ejército de Estados Unidos en esta época únicamente contaba con alrededor de 50000 ó 60000 hombres. (J. Fred Rippy, 1971:335).

Comunicado del secretario de Guerra al secretario de Estado, 5 de febrero de 1912, en U.S. Department of State, Record Group 59, file 812.00. Records of the Department of State Relating to the Internal Affairs of Mexico, 1910-1929 (Microcopy 274), National Archives and Records Service, Washington, D.C. documento núm. 2738 (de aquí en adelante, se citará este fondo como NA/RG 59, f812.00, seguido del número del documento); The Washington Post, 4 de febrero de 1912. 
En contestación a las admoniciones de Colquitt, Santiago Mestas, el alcalde rebelde de Ciudad Juárez, declaró que, en el caso de una lucha, las fuerzas beligerantes combatirían fuera de la ciudad. La anticipada batalla no ocurrió, puesto que el 3 de febrero de 1912, Pascual Orozco, quien había sido el jefe militar más destacado durante la insurrección maderista y era comandante de las fuerzas rurales en Chihuahua, logró convencer a los rebeldes para que se rindieran sin pelear. Orozco orden 6 el traslado de los soldados rebeldes a Chihuahua, dejando que el distrito volviera a un estado de calma. (El Paso Morning Times, 4 de febrero de 1912; Sánchez, 1976-1977:15; Aldama, 1964:279-280).

No obstante, los disturbios continuaron en otras partes del estado. El 2 de febrero de 1912, en Chihuahua, la capital, el capitán Refugio Mendoza del 23o. Cuerpo Rural se amotinó con una porción de su tropa, y, al liberar a Antonio Rojas y sus partidarios de la penitenciaría, se escaparon al noreste del estado. Al mismo tiempo, Braulio Hernández, antiguo secretario del gobierno del estado, en unión con otros simpatizantes vazquistas, se declaró en rebelión con el "Plan de Santa Rosa". Hernández y sus hombres salieron de Chihuahua y en Coyame, en el camino a Ojinaga, se unieron a las fuerzas de Herminio R. Ramírez, quien también se había levantado en armas. También por estas fechas, se sublevó en Casas Grandes un grupo de rurales maderistas que desconocieron a su jefe, el mayor Juan Talamantes, al que se unieron varios habitantes de la región. El grupo, encabezado por José Inés Salazar, Emilio Campa y Demetrio Ponce, de antigua filiación magonista, proclamaron el lema de "Tierra y Libertad" del Partido Liberal Mexicano.

Los esfuerzos del gobierno maderista para enviar tropas adicionales a Chihuahua para hacer frente a los rebeldes condujeron a otras situaciones que empeoraron las relaciones entre México y Estados Unidos. La Secretaría de Relaciones Exteriores en México pidió permiso del Departamento de Estado estadounidense para poder enviar un contingente de soldados mexicanos de Eagle Pass, Texas, a El Paso a través del territorio estadounidense, con objeto de reemplazar a la tropa juarense que había sido transferida a Chihuahua bajo las órdenes de Orozco. Los soldados no estarían armados, y el ejército proporcionaría una "escolta honoraria" para las fuerzas mexicanas. El gobierno de Estados Unidos, en dos ocasiones anteriores, había otorgado permiso para semejantes traslados, y esta última

\footnotetext{
6 Aunque los dirigentes de la revuelta en Casas Grandes nombraron a Pascual Orozco como "General en Jefe del Ejército Libertador", éste tardó un mes en aceptar el cargo (Almada, 1964:272, 280-282 y 291-292; Sánchez, 1976-1977:15-17 y 42-43). Una transcripción del Plan de Santa Rosa se encuentra en Manuel González Ramírez, 1954:93-94).
} 
solicitud era considerada como asunto rutinario. De hecho, las autoridades estatales y nacionales consideraban que el proyecto facilitaría la restauración de un estado de paz en la región fronteriza (El Paso Morning Times, 9 de febrero de 1912; The Washington Post, 9 de febrero de 1912).

No obstante, el gobernador Colquitt comenzó a reconsiderar la conveniencia de esta propuesta después de la publicación de un artículo en $\mathrm{El}$ Paso Morning Times titulado "El Paso está en grave peligro", en el cual se refería a la tropa federal mexicana como "pequeños soldados prietos que habían combatido en favor del dictador Díaz". Al mismo tiempo, se advertía que estos refuerzos serían atacados "en las mismas calles de El Paso antes de que pudieran cruzar al territorio mexicano." (El paso morning Times, 9 de febrero de 1912). Influido por tales intentos de provocar la histeria en la región fronteriza, el gobernador Colquitt informó al secretario de Estado de que el estado de Texas retiraba su aprobación para el movimiento de la tropa mexicana, aunque, dado que estaba algo inseguro relativo a los poderes de la autoridad federal de poder llevar a cabo el plan a pesar de la oposición estatal, ordenaba que los Texas Rangers no deberían obstaculizar el tránsito de los soldados mexicanos mientras éstos no estuviesen armados y bajo escolta. De hecho, la administración de Taft en esta ocasión no había contemplado acceder a la petición del gobierno mexicano; tampoco estaba dispuesto a permitir el pasaje de fuerzas mexicanas bajo cualquier circunstancia si existía oposición por parte de las autoridades estatales o locales. Confrontado con la posibilidad de un rechazo a su petición, el gobierno maderista la retiró bajo pretexto de que el movimiento de tropa contemplado requeriría la aprobación del senado mexicano, que no celebraba sesiones en estos momentos y que, debido a que la situación en el norte de México se había mejorado, ya no era necesario negociar tal traslado (El Paso Morning Times, 11 de febrero de 1912; New York Times, 17 de febrero de 1912).

A pesar de la cancelación del proyecto, el periódico El Paso Morning Times continuó publicando artículos inflamatorios, con encabezados tales como "El gobernador Colquitt desafía a las autoridades en Washington" y "Las protestas por parte de El Paso cancelan la contemplada violación de las leyes de neutralidad que pudieran haber puesto en peligro la ciudad, así como las vidas y propiedades de los estadounidenses en el estado de Chihuahua". Se refería a las "complicaciones diplomáticas" que habían surgido y que involucraban a los gobiernos respectivos de Texas, Estados Unidos y México (El Paso Morning Times, 10 de febrero de 1912). ${ }^{7}$

7 Ver también los editoriales titulados "Another Outrage on Texas" y "United States Would Violate Own Laws", en este mismo periódico, 9 y 11 de febrero de 1912, respectivamente. 
De hecho, el desacuerdo entre las autoridades tejanas y federales respecto a la política en torno a la frontera habían llegado a tal grado que el gobiemo de Colquitt estaba siguiendo su propio curso en este sentido. En una carta dirigida al ayudante general del estado, Henry Hutchings, en El Paso, inmediatamente después del incidente relativo al movimiento de la tropa, el gobernador declaraba que "quería que se entendiera que ni el estado de Texas ni cualquiera de sus oficiales intervendrá en la política de México, pero estamos resueltos a proteger a nuestra gente de las consecuencias de la lucha entre las distintas bandas revolucionarias y la tropa del gobierno mexicano".

Dentro de este contexto de inicios de otro gran levantamiento armado en Chihuahua, así como en un ambiente de miedo y paranoia que éste provocó en El Paso, ocurrí el episodio conocido como "la invasión del tranvía". El 14 de febrero de 1912, al teniente 1ro. Benjamín W. Fields le fue ordenado llevar a 19 soldados del 180 . Regimiento del ejército estadounidense al puente internacional de Santa Fe para relevar a la tropa que vigilaba este punto. Un carro de tranvía fue enviado desde el depósito en el centro de El Paso hasta el Fuerte Bliss para efectuar el traslado. Fields había llegado a El Paso procedente del Fuerte Whipple apenas tres días antes y no conocía la ciudad. Como Fields lo declaró en un testimonio realizado después del evento, un soldado de la guarnición del Fuerte Bliss le había informado que no tendría que bajarse del tranvía, que lo llevaría a él y sus hombres directamente a su destino; además, afirmó, había consultado personalmente un mapa que mostraba que la ruta del tranvía seguía hasta el puente de Santa Fe, pero no se percató de que una porción de la línea pasaba por Ciudad Juárez. ${ }^{8}$

A consecuencia de la ignorancia del oficial, el tranvía llegó a correr una distancia de tres cuadras aproximadamente dentro del territorio mexicano, antes de tener que pararse frente a una multitud de mexicanos enfurecidos, entre ellos el alcalde Mestas, quien blandía una pistola grande. Muchos ciudadanos, en anticipación de una intervención estadounidense en gran escala, comenzaron a armarse y formarse en grupos. Afortunadamente, el cónsul mexicano en El Paso, Enrique C. Llorente, pronto llego

\footnotetext{
8 Telegrama del coronel E.Z. Steever, comandante de la 4ta. Caballería, El Paso, Texas, 15 de febrero de 1912, citado en un informe de H.L. Stimson, secretario de Guerra, al secretario de Estado, 16 de febrero de 1912; Huntington Wilson, el secretario de Estado suplente, al embajador mexicano en Washington, D.C., 26 de febrero de 1912, ambos en NA/RG 59, f812.00/2807 y 2825 respectivamente; El Paso Morning Times, 16 de febrero de 1911. La línea de tranvías eléctricos que cruzaban de El Paso a Ciudad Juárez fue inaugurada en 1903 por la compañía El Paso City Lines. De 1882 a 1902, había existido una línea de tranvías tirados por mulas, empresa que fue fundada por los señores Zack T. White y Joseph Magoffin. Benjamín Herrera Vargas (s/f :290).
} 
para dar explicaciones sobre el asunto. Los soldados estadounidenses fueron desarmados y se les permitió regresar al otro lado de la frontera, donde el teniente Fields fue arrestado y encarcelado en el Fuerte Bliss mientras que se investigaban los hechos del caso (El Paso Morning, 17 de febrero de 1912; Belding, 1958:108; Aldama, 1964:289; Lister, 1966:219). Varios juarenses expresaron su descontento al enterarse de esta decisión. Algunos opinaban que los soldados detenidos debieran haber sido retenidos hasta llevar a cabo una investigación plena de los hechos, dado que, una semana previa (el 6 de febrero), 13 mexicanos armados que habían entrado al territorio tejano cerca de La Noria, Nuevo México, habían sido encarcelados durante dos días en el Fuerte Bliss antes de ser dejados en libertad para volver a México. ${ }^{9}$

Aunque se puso fin al incidente inicial, pronto surgieron otras confrontaciones de mayor magnitud. Una hora después de haber ocurrido el incidente, todos los estadounidenses habían salido de Ciudad Juárez, se había interrumpido el servicio de tranvías con El Paso, se había cerrado el hipodromo y las cantinas, y los vigilantes en los puentes internacionales prohibieron la entrada de extranjeros a México. Una guardia compuesta por 25 soldados fue enviada por las autoridades municipales de Ciudad Juárez al consulado de Estados Unidos para proteger al cónsul Thomas D. Edwards y su personal. Aunque no hubo daños o destrucción de sus propiedades, varios residentes estadounidenses del pueblo aseveraron que habían sido insultados por mexicanos armados al abandonar el lugar.

Entretanto, el grupo de juarenses armados que se había formado continuó reclutando a voluntarios adicionales, incluyendo a algunos residentes mexicanos de El Paso. Eventualmente llego a contar con 300 miembros aproximadamente, encabezados por el doctor Teodoro López, con su cuartel general ubicado en la calle Lerdo. ${ }^{11}$ Los jefes de esta unidad se dirigieron a las oficinas del presidente municipal para pedir armamento adicional, pero, al no obtenerlo, se pusieron a registrar toda la ciudad en

9 Los hombres arrestados habían sido originalmente apostados en Palomas, Chihuahua, como vigilantes en el servicio de la aduana fronteriza mexicana y habían cruzado la línea divisoria a Estados Unidos al recibir noticias de la próxima llegada procedente de Casas Grandes de una partida de rebeldes vazquistas encabezados por el coronel Roque Gómez ( $E l$ Paso Morning Times, 7 y 9 de febrero de 1912).

${ }^{10} \mathrm{El}$ cónsul Edwards aceptó los servicios de sólo algunos de los guardias enviados. Telegrama de Thomas D. Edwards, el cónsul estadounidense en Ciudad Juárez, al secretario de Estado, 15 de febrero de 1912, en NA/RG 59, f812.00 y El Paso Morming Times (16 de febrero de 1912).

${ }_{11}$ Esta fuerza estaba compuesta de una mezcla de policías, aduaneros y ciudadanos voluntarios a quienes habían sido entregadas armas por las autoridades municipales (El Paso Moming Times, 11 de febrero de 1912). 
busca de armas ligeras y otro material. Al mismo tiempo, telegrafiaron a las autoridades estatales en Chihuahua, pidiendo que se enviara un furgon de municiones para apoyar en la defensa de la ciudad (El Paso Morning Times, 17 de febrero de 1912). ${ }^{12}$

Los manifestantes comenzaron a dispersarse y volver a sus casas y negocios después de un breve discurso pronunciado por el cónsul estadounidense Edwards a las cinco de la tarde en el cual dio las razones por el cruce ilegal. Poco después, llegó un mensaje del gobernador de Chihuahua, que afirmaba que no existía ningún conflicto internacional con el gobierno de Estados Unidos y que las autoridades militares y civiles en El Paso habían proporcionado las explicaciones y disculpas correspondientes al caso (Almada, 1964:290).

En El Paso, un grupo de residentes mexicanos, lidereados por la esposa de un señor de apellido León Martínez, realizaron una demostración en contra del cónsul Llorente por haber defendido a los soldados estadounidenses que habían cruzado la frontera. En consecuencia, el ayudante general Hutchings, quien ya estaba en El Paso con motivo de investigar la situación local, ordenó la movilización inmediata de la Compañía " $K$ " de la Guardia Nacional de Texas en El Paso, después de recibir un telegrama del gobernador Colquitt para este efecto. Los hombres fueron enviados a hacer guardias alrededor del consulado mexicano y de las cárceles de la ciudad y del condado (El Paso Morning Times, 17 y 18 de febrero de 1912).

Muchos estadounidenses residentes de otras ciudades y pueblos del norte de México, tales como Torreón, Parral, Casas Grandes, etcétera, también fueron sujetos a insultos y demostraciones en su contra. El dirigente vazquista Gonzálo Enrile emitió un manifiesto en el cual acusaba al presidente de Estados Unidos de ser "responsable por los problemas de México y América Latina". Se planeaba distribuir este manifiesto entre la población de Ciudad Juárez y el norte de México en general (New York Times, 25 de febrero de 1912). Confrontados con esta situación y temerosos de posibles ataques por parte de los habitantes mexicanos de estas regiones o de los grupos rebeldes que operaban en ciertos distritos del estado, muchos extranjeros decidieron refugiarse en El Paso y otras

\footnotetext{
12 En parte, estas medidas de defensa fueron tomadas en preparación para repeler un posible ataque por parte de rebeldes vazquistas desde el distrito de Casas Grandes en el noroeste del estado. En la noche del 5 de febrero, el ruido provocadopor algunos disparos, al mismo tiempo en que se veían las luces delanteras de una locomotora acercándose a la ciudad desde el oeste, habían producido un estado de pánico en la población. Aunque el presunto asalto pronto mostró ser infundado, ilustró el estado de inquietud en que vivían los juarenses durante aquel periodo (El Paso Moming Times, 6 de febrero de 1912).
} 
ciudades de Texas. (El Paso Morning Times, 17, 18 y 20 de febrero de 1912; The Washington Post, 24 de febrero de 1912).

Para entender plenamente la reacción repentina en contra de los estadounidenses por parte de la población mexicana de Ciudad Juárez, El Paso y otros lugares, hay que reflexionar en general sobre el trasfondo histórico de las relaciones entre México y Estados Unidos. Para principios de la revolución, había surgido en México una ola de arraigado naćionalismo, así como cierto espíritu de antiamericanismo. Éste tuvo sus orígenes en las guerras de 1835-1836 y 1846-1848, a través de las cuales Estados Unidos se anexó más de la mitad del territorio del México de entonces. También se debió a las incursiones filibusteras de la década de 1850-1860, al resentimiento de los mexicanos a la favorable posición económica disfrutada por los inversionistas estadounidenses en México durante el porfiriato, su disgusto por el maltrato de sus semejantes en Estados Unidos, entre otros muchos factores. El linchamiento del joven mexicano Antonio Rodríguez, el 4 de noviembre de 1910, acusado de haber asesinado a una mujer texana, prendio fuego a una serie de disturbios antiestadounidenses en las ciudades de México y Guadalajara. Tales incidentes, junto con el creciente ambiente de violencia revolucionaria, motivaron a muchos estadounidenses y mexicanos adinerados a mudarse a Estados Unidos. El envío de unidades adicionales del ejército estadounidense a la frontera en marzo de 1911 provocó miedo entre la población mexicana ante la posibilidad de una intervención militar (James, 1963:443; Turner, 1967:502507 y 1968:35-44, 53-61 y 208-219). La reanudación en febrero de 1912 de las discusiones en torno de la conveniencia de aumentar el número de tropas en la zona fronteriza y de intervenir militarmente en México, reavivó este miedo, que, agregado a los otros factores antes mencionados, increment $\delta$ el sentimiento de antiamericanismo.

Para el 16 de febrero - un día después- los disturbios en Juárez y El Paso se habían terminado y el orden restaurado (El Paso Morning Times, 17 de febrero de 1912). El gobierno mexicano, por su parte, no expresó ninguna actitud de alarma respecto al incidente, mientras que la administración de Taft ofrecio una disculpa formal, al atribuir el error al hecho de que el teniente Field era "ignorante de la topografía de El Paso y del derrotero del tranvía, y creyendo tener derecho a caminar en el tranvía hasta su destino". ${ }^{13}$

\footnotetext{
13 Huntington Wilson, el secretario de Estado suplente, al embajador mexicano en Washington, D.C., 26 de febrero de 1912, en NA/RG 59, F812.00/2825; Gilberto Crespo y Martínez, el embajador mexicano en Washington, D.C., al secretariode Relaciones Exteriores en México, 5 de marzo de 1912, en Isidro Fabela y Josefina E. Fabela (1960-1973:161); Boletín oficial de la Secretaria de Relaciones Exteriores (1912:260-261); Luis G. Zorrilla (1966:218).
} 
En El Paso, sin embargo, el incidente y sus consecuencias condujeron a una reanudación de las peticiones de los sectores privados y gubernamentales en favor de la intervención en México, o por lo menos una muestra de fuerza militar a lo largo de la frontera. El periódico $\mathrm{El} \mathrm{Paso}$ Morning Times publicó editoriales con títulos como "The Reign of the Mexican Vagabond" (El dominio del vagabundo mexicano) y "México Must Clean Out the Vagabonds" (México tiene que librarse de los vagabundos), que declaraban que México en general estaba infestado de bandidos, y que las condiciones inestables amenazaban la seguridad personal de los viajeros y residentes extranjeros (El Paso Morning Times, 17 y 18 de febrero de 1912). Dos diputados demócratas del estado de Texas, los señores Burleson y Smith, solicitaron que Taft ordenara una segunda movilización del ejército en la zona fronteriza. ${ }^{14}$ Declararon que, aunque habían cesado los ataques e insultos contra los estadounidenses, sus connacionales en México estaban constantemente en peligro de ser maltratados por los bandidos y rebeldes.que merodeaban en muchas regiones del norte y estarían más seguros con un cuerpo de tropa estadounidense en la frontera, listo para intervenir en el caso de cualquier emergencia (New York Times, 17 de febrero de 1912; El Paso Morning Times, 19 de febrero de 1912).

Durante la última semana de febrero de 1911, una delegación formada por algunos de los comerciantes más destacados de El Paso, encabezados por el alcalde Thomas Kelly, viajo a Washington, donde pidió al secretario de Guerra Stimson y al general Leonard Wood, el jefe del estado mayor del ejército, que el gobierno federal enviara tropas a Ciudad Juárez para patrullar la ciudad, hasta que el gobierno mexicano pudiera restaurar el orden. Según la delegación, los "bandidos" que ocupaban el pueblo fronterizo se habían apoderado de las propiedades estadounidenses. También aseveraban que Ciudad Juárez, con una población de 14000 habitantes, era un suburbio de El Paso, que tenía 45000 ; además, señalaban que alrededor de 7000 personas pasaban diariamente entre los dos pueblos con motivo de compras y otros asuntos de negocios. La delegación protestó en contra de cualquier reducción de las fuerzas que patrullaban la línea divisoria; criticaba, en particular, la decisión del congreso de dar de baja a cinco regimientos de caballería. Declaró que el pueblo de El Paso buscaba la protección del gobierno federal, pero, si no se decidía a proporcionarla, estaba resuelto a defenderse con sus propios recursos

${ }^{14}$ La primera movilización había ocurrido el año anterior, en marzo de 1911 (Coerver, 1984:23). 
(New York Times, 24 de febrero de 1912; The Washington Post, 24 de febrero de 1912). Por estas mismas fechas, por ejemplo, Peyton J. Edwards, el comisario del condado, estaba ocupado en comisionar a todos aquellos ciudadanos que poseían armas a formar un posse comitatus gigante, en caso que fuera necesario actuar en este sentido (El Paso Morning Times, 25 de febrero de 1912; New York Times, 25 de febrero de 1912). Como último punto, la delegación pidió que el teniente Fields no fuera castigado tan severamente, dado que sus acciones no representaban ningún intento para desobedecer las órdenes de sus oficiales superiores; más bien, se debieron a su falta de conocimiento del entorno geográfico de las ciudades fronterizas (The Washington Post, 24 de febrero de 1912).

Stimson rechazó la propuesta de una intervención militar en México en tanto que las vidas y propiedades de los estadounidenses residentes de allíno estuvieran en peligro, aunque acordo en enviar refuerzos adicionales a la frontera. Estos refuerzos consistieron en el 220. Regimiento de Infantería y tres baterías de la 3ra. Sección de Artillería de Campaña, bajo las órdenes de los coroneles D.A. Frederick y Samuel D. Sturgis respectivamente, que fueron transferidos a El Paso desde el Fuerte Sam Houston en San Antonio. (El Paso Morning Times, 24, 25 y 26 de febrero de 1912; The Washington Post, 24 de febrero de 1912; New York Times, 25 de febrero de 1912).

En cuanto a Fields, Stimson contestó a la delegación de El Paso de que, dado que el coronel Steever había ordenado que el subteniente fuera sometido a un consejo de guerra, no tenía otra alternativa más que aprobar tal acción como medida disciplinaria, con el propósito de demostrar a México que el gobierno estadounidense tenía la intención de observar estrictamente las leyes de neutralidad, no sólo referente a aquellos mexicanos que cruzaran la frontera con armamento, sino también respecto a los estadounidenses que hicieran lo mismo sin autorizacion. (The Washington Post, 24 de febrero de 1912). Al fin y al cabo, Fields, aunque fue declarado culpable por el consejo de guerra, recibio únicamente una reprimenda por sus acciones. Fue dejado en libertad y restituido como oficial en servicio activo. Al comentar sobre el caso, el general de brigada Ramsey D. Potts declaró que "el teniente Fields cometió a sabiendas las acciones de las cuales estaba acusado", y que "tales acciones no fueron el resultado de un desconocimiento de la línea divisoria entre México y Estados Unidos, ni perdonable debido a su incompetencia en el cumplimiento de sus deberes". Agregó que el joven oficial había "puesto en duda el grado de inteligencia con que supuestamente un oficial debería contar, así como mostrado su poca apreciación de las responsabilidades de su cargo" (The Washington Post, 26 de febrero de 1912). 
Por su parte, el gobernador Colquitt escribio al presidente Taft para pedir también que el gobierno federal enviara a soldados para ocupar a Ciudad Juárez. Al caracterizar la situación en la región de El Paso-Juárez como "crítica" y con "la mayor parte de la población de Chihuahua en un estado de rebelión en contra del gobierno mexicano", argumentaba en favor de la "ocupación pacífica" de Ciudad Juárez por las tropas estadounidenses hasta que se pudiera restaurar el orden. Según Colquitt, el saqueo practicado por los soldados de la guarnición de Juárez había estimulado el robo entre la población civil mexicana de las dos ciudades. Un año antes, durante la insurrección maderista de 1910-1911, Colquitt había enviado una carta semejante a Taft, y desde entonces, su opinión referente al asunto no había cambiado. ${ }^{15}$

Durante una reunión en la Casa Blanca entre el presidente Taft, los senadores Lodge, Bacon, y Stone del comité sobre Relaciones Exteriores y los senadores Bailey y Culbertson de Texas, se discutio la posibilidad de que surgiera una situación en que fuera necesario enviar a soldados a México para obligar a las fuerzas beligerantes a combatir en un punto relativamente distante de la frontera con Estados Unidos. Acordaron en que tal acto no podría ser considerado una invasión ni acción de guerra, puesto que existía un precedente histórico para el desembarco de marines en territorio extranjero en la ausencia de soldados del gobierno constituido legítimamente para ofrecer protección a los residentes estadounidenses $(E l$ Paso Morning Times, 26 de febrero de 1912).

No obstante, la gran batalla que se pensaba ocurriría en el caso de un ataque rebelde a Ciudad Juárez, que hubiera creado una situación parecida de la que fue discutida en la reunión de la Casa Blanca, ${ }^{16}$ no se materializo;

15 O.B. Colquitt al presidente Taft, 24 de febrero de 1912, en NA/RG 59, f812.00/2986. Al momento de escribir a Taft, había tres hombres en rivalidad para ser reconocidos como alcalde de Ciudad Juárez: Santiago Mestas, cantinero nombrado al puesto por los amotinados; EmilianoEnríquez, residente de Chihuahua y el candidato postulado por el gobernador estatal Abraham González; y Juan N. Medina, oficial del ejército federal con el rango de mayor, quien se convertiría en miembro del estado mayor de Francisco Villa en 1913. Se rumoraba que Mestas, rebelde vazquista, había sido el instigador de mucho del sentimiento antiestadounidense que surgió después de la entrada accidental del tranvía a México, así como el organizador principal del reclutamiento de voluntarios para resistir la "invasión" imaginaria. El Paso Morning Times, 17 de febrero de 1912).

16 Obviamente, algunas de estas "situaciones" podrían ser creadas por medio de complots, conspiraciones, etcétera. Por ejemplo, el arresto de los estadounidenses Thomas Hifrin y F.R. Hamiaad en las afueras de Ciudad Juárez por estas fechas, dio lugar a rumores de un supuesto plan para provocar una intervención militar por parte de Estados Unidos en México. Fue reportado que, en el momento de su detención, estos hombres portaban dos pistolas, un rifle, dos cajas de parque y un pico del tipo utilizado por los mineros. Su plan, se aseveraba, consistía en provocar un motín con objeto de que las fuerzas americanas estarían obligadas 
cuando el grupo de rebeldes vazquistas dirigidos por Emilio Campa lanzaron, el 27 de febrero, su asalto contra el pueblo, la pequeña guarnición de defensores civiles se rindió después de haberse intercambiado algunos disparos con los atacantes (Aldama, 1964:292; Sánchez, 1976- 1977:17). Después de la captura de la guarnición por los insurrectos, los debates en torno a la conveniencia de intervenir en México cesaron durante un tiempo.

\section{COMENTARIOS FINALES}

Los problemas entre México y Estados Unidos que surgieron a raíz del incidente en torno a la supuesta "invasión del tranvia" exacerbaron las tensiones ya existentes entre las dos naciones provocadas por las actividades conspiratorias de los rebeldes mexicanos en territorio estadounidense, el tráfico de armas y hombres a través de la frontera, los daños - a veces presuntos- a las propiedades y vidas de ciudadanos de Estados Unidos en México y en los pueblos fronterizos de Texas, Nuevo México y Arizona, etcétera. En particular, el episodio señaló un cambio distinto en las relaciones entre los ciudadanos de El Paso y Ciudad Juárez. Durante la insurrección maderista, éstas eran más o menos cordiales, como habían sido durante la época porfiriana en general, pero, para 1912, esta situación se había deteriorado considerablemente. En este sentido, la llamada "invasión" constituyó la primera indicación de una desconfianza creciente entre los habitantes de estas ciudades y entre los ciudadanos de los dos países en general. Por último, como una expresión conciente de la política del intervencionismo que había sido abogada por muchos estadounidenses una tras otra vez desde el inicio de la lucha, prefiguró hasta cierto punto las verdaderas intervenciones armadas en gran escala que ocurririan en los años 1914, 1916 y 1919, durante la fase constitucionalista de la revolución.

a cruzar la frontera para restaurar el orden. Se decía que Hifrin y Hamiaad estaban dirigidos por un destacado soldado de fortuna, también de nacionalidad estadounidense, y que había sido depositada una gran cantidad de dinero para ellos en un banco en El Paso. Circulaban muchos otros rumores en torno a la posibilidad de la intervención militar en México y de la guerra en general; de hecho, como el periódico El Paso Moming Times señalaba, existía el mismo ambiente de conmoción que en abril y mayo del af́o anterior, cuando los maderistas sitiaron a Ciudad Juárez (El Paso Moming Times, 25 de febrero de 1912). 


\section{BIBLIOGRAFÍA}

ALMADA, Francisco R. 1964. La revolución en el estado de Chihuahua, v.1, Instituto Nacional de Estudios Históricos de la Revolución Mexicana, México.

COERVER, Don M. y Linda B. Hall. 1984. Texas and the Mexican Revolution: A Study in State and National Border Policy, San Antonio, Tex., Trinity University Press.

FABELA, Isidro y Josefina E. Fabela, (editores). 1960-1973. Documentos historicos de la Revolución Mexicana, Editorial Jus/Fondo de Cultura Económica, México, v. 7.

FLORENCE C. Lister y Robert N. Lister. 1966. Chihuahua: Storehouse of Storms, University of New Mexico Press, Albuquerque, N.M.

GONZÁLEZ Ramírez, Manuel. 1954. Planes políticos y otros documentos, Fondo de Cultura Económica, México.

HENDERSON, Peter V.N. 1979. Mexican Exiles in the Borderlands, El Paso, Tex., Texas Western Press, University of Texas, El Paso.

HERRERA Vargas, Benjamín. s/f. ;Aqui Chihuahua! cuna y chispa de la Revolución Mexicana, s.p.i.

HOFFMAN, Nancy J. "The Revolutionary North and the Vasquez Gómez", en Matt S. Meier, ed., Latin American Frontiers (Proceedings of the Pacific Coast Council on Latin American Studies, 23rd. Annual Meeting, v.7, 1980-81.

JAMES, Daniel. 1963. Mexico and the Mexicans.

SÁNCHEZ Lamego, Miguel A. 1976-1977. Historia militar de la Revolución Mexicana en la época maderista, Instituto Nacional de Estudios Históricos de la Revolución Mexicana, v.3, México.

Secretaría de Relaciones Exteriores. 1912. Boletín oficial de la Secretaría de Relaciones Exteriores, v. 33, núm. 5, 31 de marzo.

RIPPY, J. Fred. 1971. The United States and Mexico, AMs Press, Nueva York, reimp. de la edición de 1931.

TURNER, Frederick C. 1967. "Anti-Americanism in Mexico, 19101913", en Hispanic American Historical Review, v. 47, núm. 4 noviembre.

- 1968. The Dynamic of Mexican Nationalism, Chapel Hill, N.C. University of North Carolina Press.

ZORRILLA, Luis G. 1966. Historia de las relaciones entre México y los Estados Unidos de América, 1800 y 1958, v. 2, Editorial Porrúa, México. 
INTERVENCIÓN POR EQUIVOCACIÓN: LA INVASIÓN DEL TRANVIA

\section{HEMEROGRAFIA}

El Paso Morning Times, 1 y 2 y 16 de febrero de 1911

El Paso Morning Times, 2, 3, 4, 5, 6, 7, 9, 10, 11, 16, 17, 18, 19, 20, 24, 25 y 26 de febrero de 1912.

The Washington Post, 4, 9, 24 y 26 de febrero de 1912.

New York Times, 17, 24 y 25 de febrero de 1912. 